University of New Hampshire

University of New Hampshire Scholars' Repository

6-2010

\title{
Place effects on environmental views
}

\author{
Lawrence C. Hamilton \\ University of New Hampshire, lawrence.hamilton@unh.edu \\ Chris R. Colocousis \\ University of New Hampshire \\ Cynthia M. Duncan \\ University of New Hampshire, Mil.Duncan@unh.edu
}

Follow this and additional works at: https://scholars.unh.edu/soc_facpub

Part of the Sociology Commons

\section{Comments}

This is the pre-peer reviewed version of the following article: Hamilton, L.C., Colocousis, C.R., Duncan, C.M. Place effects on environmental views. (2010) Rural Sociology, 75 (2), pp. 326-347, which has been published in final form at https://dx.doi.org/10.1111/j.1549-0831.2010.00013.x. This article may be used for non-commercial purposes in accordance with Wiley Terms and Conditions for Self-Archiving.

\section{Recommended Citation}

Hamilton, L.C., Colocousis, C.R., Duncan, C.M. Place effects on environmental views. (2010) Rural Sociology, 75 (2), pp. 326-347.

This Article is brought to you for free and open access by the Sociology at University of New Hampshire Scholars' Repository. It has been accepted for inclusion in Sociology Scholarship by an authorized administrator of University of New Hampshire Scholars' Repository. For more information, please contact Scholarly.Communication@unh.edu. 
AUTHORS' DRAFT. Final version published at:

Hamilton, L.C., C.R. Colocousis \& C.M. Duncan. 2010. "Place effects on environmental views." Rural Sociology 75(2):326-347. doi: 10.1111/j.1549-0831.2010.00013.x

\title{
PLACE EFFECTS ON ENVIRONMENTAL VIEWS
}

Lawrence C. Hamilton

Chris R. Colocousis

Cynthia M. Duncan

\section{Acknowledgments}

This research has been supported by grants to the Carsey Institute from the W.K. Kellogg, Ford, and Mary K. Reynolds Babcock Foundations, and by the Neil and Louise Tillotson Fund of the New Hampshire Charitable Foundation.

\begin{abstract}
How people respond to questions involving the environment depends partly on individual characteristics. Characteristics such as age, gender, education and ideology comprise the well-studied "social bases of environmental concern," which have been explained in terms of cohort effects or of cognitive and cultural factors related to social position. It seems likely that people's environmental views depend not only on personal characteristics, but also on their social and physical environments. This hypothesis has been more difficult to test, however. Using data from surveys in 19 rural U.S. counties, we apply mixed-effects modeling to investigate simple place effects with respect to locallyfocused environmental views. We find evidence for two kinds of place effects. (1) Net of individual characteristics, specific place characteristics have the expected effect on related environmental views. Local changes are related to attitudes about regulation and growth. For example, respondents more often perceive rapid development as a problem, and favor environmental rules that restrict development, in rural counties with growing populations. Moreover, they favor conserving resources for the future rather than using them now to create jobs in counties that have low unemployment. (2) After controlling for county growth, unemployment and jobs in resource-based industries, and also for individual socialposition and ideological factors, there remains significant place-to-place variation in mean levels of environmental concern. Even with both kinds of place effects in the models, the individual-level predictors of environmental concern follow patterns expected from previous research. Concern increases with education among Democrats, whereas among Republicans, the relationship is attenuated or reversed. The interaction marks reframing of environmental questions as political wedge issues, through nominally scientific counter-arguments aimed at educated, ideologically receptive audiences.
\end{abstract}




\section{Introduction}

Have conservation or environmental rules that restrict development generally been a good thing for your community, a bad thing, or have they had no effect?

We know that how people respond to questions involving the environment depends partly on who they are. Age, gender, ethnic identity and education often predict environment-related views. In rural communities, newcomer/oldtimer divisions can develop. Across communities of all types, ideologies affect how real, and how urgent, individuals perceive environmental problems to be. Environmental sociologists and others have built a body of knowledge concerning what Van Liere and Dunlap (1980) termed "the social bases of environmental concern." Cognitive, social-psychological and cultural dimensions related to social position help us understand the demographic bases, as seen particularly in the literature on environmental risk perceptions (e.g., Finucane et al. 2000).

Equally plausible but less studied is a second proposition: people's environmental views depend partly on where they are. Regarding the conservation-rules question above, for example, might not people's views vary with the actual conditions in the environment - broadly defined, and imperfectly perceived - around them? Have they seen such rules enforced to protect their community from unwanted development, or conversely, blamed for lost jobs? Would an alleged tradeoff between conserving resources or using them to create jobs resonate differently in the Colorado Rockies and Kentucky coal country? Might individuals' opinions about rapid development or global warming depend not just on their education, social position or ideology, but also on recent population or climate trends where they live? Although such hypotheses sound reasonable or even obvious, they are problematic to test (for example, see commentary by Brody and Zahran (2007) on the air pollution analysis of Jacquemin et al. (2007)). Bringing the environment back into environmental-concern research requires data in which environmental as well as individual characteristics are represented by independently measured variables, and analyses that adjust for unmeasured place-to-place variations. Most survey and case study designs do not attempt this.

The 2007 Community and Environment in Rural America (CERA) surveys provide a unique framework for testing hypotheses about environmental and individual effects on local environmentrelated views. The research design involved random sampling within selected counties, to study variations across different types of rural regions. Opinion questions on the surveys generally had a practical focus, referring to the respondent's own family or community. Two hundred to almost 1,000 interviews from each of 19 counties in nine states yield good resolution for studying effects of individual social-position and ideological characteristics - and also, net of those usual suspects, effects due to characteristics of the rural places where they live.[1] Mixed-effects models allow for random place-toplace differences as well.

In this paper we analyze the CERA data to test hypotheses that local-environment views of rural residents depend not only on individual characteristics, but also on characteristics of the places themselves. We start by reviewing results from previous research. Individual-level predictors have been widely studied, with some common though not invariant results. We also note a recently-advanced interaction hypothesis, involving education and political orientation, which reflects the increasingly polarized production of information about environmental topics. Next, we introduce the surveys and environment-related views forming our dependent variables. Response patterns vary by region, and covary as expected with county rates of population growth, unemployment or resource-based jobs. Finally, we apply mixed-effects modeling to test the hypotheses in multivariate context. The models estimate effects from individual characteristics (including the interaction) highlighted by previous research; several measured place characteristics that should be relevant to the variables studied; and unexplained place-to-place variations in levels of environmental concern. This flexible approach appears well suited for integrated society/environment research. 


\section{Findings of Previous Research}

Concern about the environment has been a rich topic for social-science research. Many studies started from the pioneering work of Dunlap and Van Liere (1978), who described the emergence of an environmentally-centered worldview as a macro-level shift from the traditional Human Exemptionalist Paradigm to a New Environmental Paradigm (NEP). A common research theme became "the social bases of environmental concern"- identifying individual characteristics associated with the NEP and other measures of concern about environmental problems (Van Liere and Dunlap 1980). Van Liere and Dunlap closed with two suggestions for future studies: focus on specific environmental issues and policies, and consider the tradeoffs between environmental quality and other widely-held values. As researchers did so, unpacking environmental concerns for different issues and contexts, they found diverse patterns of support.

Much environmental-concern research focused on background or positional factors such as age, gender, ethnicity, education and income, together with worldview, ideology or values indicators that tend to be correlated with social position (e.g., Jones and Dunlap 1992; Guagnano and Markee 1995; Klineberg, McKeever and Rothenbach 1998; Dunlap, Xiao and McCright 2001; Dietz, Fitzgerald and Shwom 2005; Dietz, Dan and Shwom 2007; Xiao and McCright 2007; Olofsson and Öhman 2006). Cognitive dimensions, particularly knowledge and risk perceptions, gained prominence as the technical complexities of problems such as climate change entered mainstream discourse (e.g., Viscusi and Zeckhauser 2005; Krosnick et al. 2006; Leiserowitz 2006; Lorenzoni and Pidgeon 2006; Slimak and Dietz 2006; Shwom, Dan and Dietz 2008; Wood and Vedlitz 2007; Whitfield et al. 2009). Variations in knowledge and risk perceptions help to interpret the social-position results. For example, women often show higher levels of concern regarding technology-driven environmental risks. The disparity reflects women's higher assessments of personal and family dangers, and men's (especially, white males') higher confidence in their own knowledge (Davidson and Freudenburg 1996; Finucane et al. 2000). Analysis of General Social Survey (GSS) data found that women expressed more sympathy for distant human or animal victims, as well (Hamilton 2008). Kahan et al. (2005:3) account for the "white male effect" through a cultural theory of risk, whereby "individuals selectively credit and dismiss asserted dangers in a manner supportive of their preferred form of social organization."

Age effects often appear, with older respondents expressing lower levels of concern (e.g., Hamilton 1985). Cohort differences provide one obvious explanation (Van Liere and Dunlap 1980). Environmental topics gained 1970s counterculture significance, grew more prominent through several waves of media attention (to such matters as toxic wastes, oil supplies and global warming), and became integrated with modern school curricula. Possibly the long timelines of some environmental problems, such as sea-level rise from global warming, make their impact seem more personally threatening to the young (Hamilton 2008).

Historically, education and political orientation have been the most consistent predictors across diverse measures of environmental concern (e.g., Van Liere and Dunlap 1980; Olofsson and Öhman 2006). Education effects presumably arose because higher education brought more information about geographically distant or seemingly abstract environmental threats. General political orientation often correlates with views regarding the environment. The effects of education and political orientation customarily have been described as additive, but recent findings suggest this is becoming less true regarding global-warming opinions, and perhaps other environmental views as well. Dunlap and McCright (2008) observed that the proportion believing that global warming is real increases with education among Democrats, and decreases with education among Republicans (also noted in Pew 2007). Hamilton (2008) detected interaction effects involving education and political orientation on four GSS items about global warming. Similar effects have been replicated in analyses of climate change items on the 2007 CERA surveys (Hamilton and Keim 2009) and on 2008 regional surveys in Michigan and New 
Hampshire (Hamilton forthcoming). These multivariate analyses all found patterns similar to the polling results: education (or self-assessed knowledge) is positively related o concern about climate change among liberals, but unrelated or negatively related among conservatives.

McCright and Dunlap (2000, 2003; also see Freudenburg 2000) describe how conservative think tanks (CTTs) mobilized opposition to the Kyoto Protocol by promoting critical reports, press releases and media appearances, often couched in scientific terms and fronted by a small number of credentialed scientists with compatible views. Ideological predispositions can filter how people process information, so they tend to retain "facts" that support what they already believe (e.g., Wood and Vedlitz 2007). If more educated audiences paid closer attention to the competing, nominally scientific claims, and selectively retained information that reinforced their ideological predispositions, that could account for the divergent relationships between education and the climate-change views of conservatives and liberals.

Jacques, Dunlap and Freeman (2008) extended McCright and Dunlap's social analysis beyond climate change, noting that since 1992 CTTs have advanced arguments that a wide range of environmental problems should not be taken seriously. As a result, support for environmental protection in general shifted from a formerly broad consensus to the status of political wedge issue. This shift amounts to a change toward greater complexity and polarization in the social bases of environmental concern.

Initially, environmental-concern research mainly asked how individual characteristics influence environment-related views. The influence of place or the environment itself on such views is more difficult to study, but has attracted growing attention. Geographic variations in levels of environmental concern (e.g. Guagnano and Markee 1995; Lorenzoni and Pidgeon 2006; Hamilton 2007b; Shwom et al. 2008) might partly represent environmental effects, but also support other interpretations because states, cities or regions differ in so many ways. Addressing environmental effects more directly, several studies have found relationships between public perceptions and objectively-measured air quality or other conditions (e.g., Elliott et al. 1999; Drori and Yuchtman-Yaar 2002; also see Jacquemin et al. 2007, and Brody and Zahran 2007). People's perceptions regarding climate change have been linked empirically to their self-reported experiences with weather (Krosnick et al. 2006), but also to geographical vulnerability from sea-level rise and natural hazards (Brody et al. 2008), and to measured winter temperature trends (Hamilton and Keim 2009).

Research often considers large-scale problems such as climate or sea level, but place characteristics should be at least equally relevant to views about local development or environmental protection, issues facing many rural communities. Change in local characteristics could particularly influence such views, due to reference bias or framing effects (change from a reference point; see Brody and Zahran 2007). By "place characteristics" here we mean not only the physical environment, but also local economic and social context. Scholars in the "new economic sociology" tradition (Grabher 2006; Convert and Heilbron 2007) emphasize ways that economic actors are embedded in social structures such as interpersonal networks, and how those structures shape economic action (e.g., Granovetter 1985; Lauer 2005). We might expand the concept of embeddedness to describe the ways that individuals' perspectives are in part structured by physical, economic and social contexts specific to particular places. Only a few aspects of context can be explicit in a particular analysis, so we should allow also for variations due to "everything else," or the countless unmeasured characteristics of places.

\section{The CERA Surveys}

In 2007, we began a study of Community and Environment in Rural America (CERA) to learn how people living in different rural areas viewed the changes in their communities and in their own lives. The first stage involved telephone interviews with 7,842 people living in 19 rural counties of nine U.S. 
states. Following an examination of socioeconomic data on more than 3,000 U.S. counties, these 19 had been chosen to represent four broad types of rural places, characterized as amenity/growth, amenity/decline, declining and chronic poverty (Hamilton et al. 2008). We selected for geographical and socioeconomic diversity as well. The CERA counties include several each from the Rocky Mountains (amenity/growth); the Pacific Northwest and Northeast (amenity/decline); Midwestern farm country (decline); and from Appalachia, the Mississippi Delta and Alabama's Black Belt (chronic poverty). Within each area, random telephone dialing, combined with callbacks and random selection of individuals within households, was used to obtain the best possible samples.

The telephone methods achieved response rates from 18 to $26 \%$, calculated according to American Association for Public Opinion Research's RR4 standard (AAPOR 2006). Such rates reflect recent trends towards declining cooperation with surveys (e.g., Pew 2004). College-educated individuals were over-represented, also a common problem. County-to-county variations tracked external criterion measures, however. The proportion nonwhite and median household income among CERA respondents correlated $r=.97$ and .70 , respectively, with 2007 estimates for their counties. Median home values and the proportion of college graduates correlated .97 and .82, respectively, with 2000 Census figures. Respondents' political preferences correlated .86 with 2004 county election results (Hamilton et al. 2008), and their perceptions of local climate change varied with regional temperature trends (Hamilton and Keim 2009). We calculated probability weights to offset design bias arising from household size, and make minor adjustments toward Census age/sex/race distributions within each region, following methods described in Lee and Forthofer (2006).

About 100 survey questions covered topics that ranged from respondents' personal background and experiences (such as family, jobs, education and life situation) to their migration history and views about local government and community. Several bulletins and an overview report (Hamilton 2007a, 2007b; Hamilton et al. 2008) present basic results from these surveys, including contrasts between regions. For example, Midwest respondents cited family as one of the main reasons for staying where they were; recreation opportunities and natural beauty appeared less important. Among Rocky Mountain respondents, these priorities were reversed. We found other interesting differences among rural regions as we compared people's resources; personal, family and migration histories; perceptions about neighbors, government and local problems; and worries or hopes for the future.

Table 1 displays three main environment-related questions from the survey. The general issues are urban sprawl or rapid development of the countryside (sprawl), tradeoffs between using natural resources to create jobs or conserving them for the future (conserve), and whether conservation or environmental rules that restrict development are good (rules). In keeping with CERA's place-oriented design, the wording of each question refers specifically to impacts or benefits for the respondent's home community.

$<<$ Table 1 about here $>>$

Overall, almost half the respondents believed that urban sprawl or rapid development had no effect on their family or community over the past five years. Less than a quarter thought it had major effects. There were some stark regional contrasts, however. In certain rural places rapid development was an overriding issue, while in others it appeared nonexistent. Similarly, conserving natural resources for the future was favored by a plurality of respondents overall, but in some places the opposite choice, using resources to create jobs, was seen as more important. Environmental rules that restrict development appear less controversial, but some places were split on this issue.

\section{Regional Patterns in Environmental Views}

Figure 1 graphs regional distributions of views concerning the effects of sprawl or rapid development. Seventy-seven percent of respondents in our Rocky Mountain counties said that 
development had minor or major effects on their family or community over the past five years. Seventyeight percent of Midwest respondents, on the other hand, said that it had no effect on their families or communities. Between these two extremes, majorities in our Pacific Northwest and Northeast counties also reported development effects. Majorities in the Appalachia and Delta counties saw no such effects.

$<<$ Figure 1 about here $>>$

These regional variations in environment-related views partly reflect variations in actual environments. Figure 2 graphs the percent of respondents perceiving major effects of sprawl or rapid development in the past five years against population change 2000-2005 (from U.S. Census estimates) for the 19 CERA counties. The strong positive correlation indicates that in places with high population growth, respondents more often (and accurately) perceive impacts from sprawl or rapid development. Growing, sprawl-aware counties include those in the Rocky Mountains, Pacific Northwest and Northeast. There also is one rapidly-growing Delta county, the site of casino development, that stands apart from its peers in Figure 2. The other Delta, Appalachia, Black Belt and Midwest counties all experienced population loss over this five-year period, which helps explain why majorities of respondents from those places reported no sprawl or rapid-development effects.

$<<$ Figure 2 about here $>>$

The supposed tradeoff between jobs and conservation can become an acrimonious issue in resource policy discussions, and several of our survey regions show signs of division. Between the poles of "Use natural resources to create jobs" and "Conserve natural resources for the future," some respondents chose the middle ground, "Creating jobs and conserving resources are both equally important." In no region was this middle ground a plurality, however. Figure 3 depicts using resources as the least popular choice, and conserving them the most popular, among Rocky Mountain, Pacific Northwest, Northeast and Midwest respondents. The survey's Appalachia, Delta and Black Belt counties, however, are relatively poor areas with high unemployment. More people in those places favored using resources to create jobs. Using resources to create jobs was a more popular response in places with high unemployment rates (not shown), and also in places where more of the jobs involved resource-based primary industries (Figure 4).

\section{$<<$ Figure 3 about here $>>$}

$<<$ Figure 4 about here $>>$

Another contentious issue of policy debates is the impact of conservation or environmental rules that restrict development. Even so, in six of our seven regions, fewer than $20 \%$ of respondents said such rules had been bad for their community (Figure 5). In the seventh, the Pacific Northwest, just above one-quarter of respondents thought the rules had been bad. Northwest respondents appear most divided on this point. The Northwest had the highest percentage who believed environmental rules are bad, and tied with the Northeast for the second-highest percentage who believe they are good. Support for environmental rules was stronger only among Rocky Mountain respondents. Majorities of Midwest, Appalachia, Delta and Black Belt respondents, in contrast, reported that environmental rules had no effect on their communities. People in rapidly-growing counties were more likely to view restrictive environmental rules favorably, as indicated by positive correlations with five-year population growth (Figure 6).

\section{$<<$ Figure 5 about here $>>$ \\ $<<$ Figure 6 about here $>>$}

Figures 1-6 show that environment-related views vary from place to place, partly in systematic ways. Objectively-measured population growth, unemployment rates and employment in primary industry correlate as expected with conceptually-related survey opinions. Points scattered around the regression lines emphasize the importance of taking other factors into account, however. CERA's unusual design - repeated surveys from selected rural areas - opens possibilities for revisiting the 
social bases of environmental concern, but with place effects considered as well. Recent developments in mixed-effects modeling provide tools well suited for such analysis.

\section{Modeling Individual and Place Effects}

Luke (2004) notes two problems with including contextual variables such as county characteristics as predictors of individual outcomes in one-level models. First, errors among individuals within units will likely be correlated. Second, it assumes that effects remain the same across units.

Mixed-effects modeling accommodates these problems by allowing for random variation in intercepts or slopes to capture the heterogeneity across units. Standard errors and tests are calculated with the clustered data structure in view. In our analysis we found no evidence for random slopes, but random intercepts proved important.

Table 2 displays results from mixed-effects logit regression of sprawl, conserve and rules (defined in Table 1) on individual characteristics and county-level indicators.[2] All models include random intercepts for each county. Individual-level predictors include eight social-position or ideologyrelated indicators highlighted in previous research:

$\begin{array}{ll}\text { sex } & 0=\text { male, } 1=\text { female; } \\ \text { race } & 0=\text { white non-Hispanic, } 1=\text { other; } \\ \text { age } & 18 \text { to } 96 \text { years; } \\ \text { income } & 1 \text { to } 6 \text { ordinal scale for household income quintiles and the top } 5 \% ; \\ \text { education } & 1=8 \text { th grade or less, to } 7=\text { postgraduate work (centered); } \\ \text { party } & 1=\text { strong Democrat, to } 7=\text { strong Republican (centered); } \\ \text { religious } & 0=\text { never attend services, to } 4=\text { attend twice weekly or more; } \\ \text { newcomer } & 0=\text { lived here more than } 5 \text { years, } 1=\text { moved here in past } 5 \text { years. }\end{array}$

To test the interaction hypothesis described earlier, we also included the term education $\times$ party. [3]

$<<$ Table 2 about here $>>$

We hypothesized that conserving resources rather than using them to create community jobs (conserve), and environmental rules that restrict development (rules), would both prove less popular in places with high unemployment. Perceptions of major effects from urban sprawl or rapid development (sprawl) seemed likely to be higher in places with growing population, or lower in places that declined. Population pressure could also affect approval of conservation or environmental rules. Furthermore, it seems plausible that respondents in places where many jobs depend on resources would be less likely to view resource conservation or environmental rules as beneficial for their communities. To test these hypotheses, we included county-level rates of unemployment, population growth and primary-sector employment as possible predictors, based on the most recent available data:[4]

$\begin{array}{ll}\begin{array}{l}\text { unemployment } \\ \text { population growth }\end{array} & \text { mean percent workforce unemployed, 2002-2007 } \\ \text { primary sector } & \text { percent employed in agriculture, forestry, hunting, fishing or mining, } \\ & 2000 \text { Census (see Figure 4) }\end{array}$

Of course, rural counties differ in countless other ways as well. To adjust for mean differences due to "everything else," we allow random intercepts to vary from county to county. Table 2 gives estimates and test probabilities for the fixed effects. Random intercepts are not estimated directly; instead, we give their estimated standard deviations. In each model, random intercepts brought a significant improvement in fit, as assessed by the likelihood-ratio tests at bottom. Given the large sample size, our discussion employs $\alpha=.01$ as the threshold for statistical significance.

Adjusted for place effects, individual respondents more often perceived major effects from urban sprawl or rapid development (sprawl) if they had lower incomes or education, or were longtime residents 
of their present community. This description fits with a pattern of rural growth involving upscale in-migration.

Net of these individual effects, we see that place characteristics matter as well. People more often perceive major sprawl effects when they live in a rapidly-growing county. This relationship (consistent with Figure 2) is not explained by individual characteristics, county unemployment or countyspecific variations in level. Both the newcomer (individual) and population growth (place) effects fit with reference-bias theory predictions: people more often perceive sprawl or development effects when they have a reference point for comparison, from their own long-term residence and/or from the past, less-developed state of their county. Individuals in counties with more primary-sector employment less often report sprawl effects, which also is a realistic perception for these particular places. We had no reason to expect that unemployment rates would influence sprawl opinions, and Table 2 agrees they do not.

All individual-level predictors except income affect support for resource conservation (conserve). Republicans, older respondents and those who frequently attend religious services were less likely to favor conservation for future generations. Women, non-minority and better-educated respondents were more likely to favor conservation. Thus, the social-position and ideological predictors of conserve (unlike the predictors of sprawl) conform to the classical patterns of environmental concern.

Newcomers to these rural areas also supported conservation. Many of them moved there because of natural amenities, and not for work in the declining resource industries. As expected, people living in high-unemployment counties were less likely to choose conservation over jobs. The conserve - primary sector correlation graphed in Figure 4 becomes nonsignificant, however, once we allow for random intercepts.

Support for environmental rules that restrict local development (rules) appears more prevalent among younger, better educated and less Republican respondents. Like conserve, rules thus follows the social-position and ideological pattern seen with more general measures of environmental concern. Controlling for individual factors, support for environmental rules was stronger in places having low unemployment, where such rules could seem economically less threatening. Support for rules also was higher in places with high growth rates, consistent with reference-bias theory. In such places, population change could be altering the environment in visible ways, and make it seem more in need of protection. Primary-sector employment, on the other hand, has no effect on rules.

By analogy with recent climate-change research described earlier, we hypothesized that concern about local environmental problems would be negatively related to the product of education $\times$ party. Table 2 shows this hypothesis supported with respect to all three dependent variables. That is, for each dependent variable, a more Republican political orientation attenuates or reverses the positive association between education and concern about impacts or support for environmental protection. [5] This interaction reflects the efficacy of campaigns to reframe environmental protection as a political wedge issue, through nominally scientific counter-arguments aimed at educated, ideologically receptive audiences (McCright and Dunlap 2000, 2003; UCS 2007; Jacques et al. 2008). As better-educated individuals selectively retain technical claims that seem consistent with their prejudices, they become more polarized in their beliefs about the need for environmental protection.

\section{Discussion}

A sample drawn from 19 rural counties makes the CERA surveys unique, but our findings appear plausible and robust. With respect to local resource conservation (conserve) or environmental protection (rules), individual social-position and ideological predictors fit the classical patterns of environmental concern. Perceived impacts from urban sprawl or rapid development ( $\mathrm{sprawl}$ ) followed a somewhat different pattern, better understood in terms of who is moving in, who lived there already, and the effect 
of reference bias. Independently-measured county characteristics affected local environmental views in the hypothesized directions as well (for other examples see Zahran et al. 2006; Brody et al. 2008).

Internally, the conclusions proved stable across alternative coding and regression strategies (notes 2-4). Although multicollinearity and outlier issues sometimes make interaction effects samplespecific, the education $\times$ party effects seen with all three dependent variables in Table 2 confirm and extend previous findings from other datasets including the General Social Survey (Hamilton 2008; also see Hamilton forthcoming). They point towards political currents that are shifting the social bases of environmental concern.

The environmental questions in CERA referred to respondents' own communities. Many of these places also have been reshaped through migration, whether by newcomers moving in or by longterm residents moving away (Johnson 2006). For some CERA regions, newcomers and long-term residents differ in basic ways such as age, education, income and politics. Even controlling for these factors, however, we found significant newcomer effects. Having arrived recently, thereby contributed to local growth, and having no long-term perspective for comparison, newcomers less often see growth as a problem. On the other hand, newcomers to many of these areas came for the amenities, and consequently are more likely than long-term residents to favor conservation.

Local changes are related to attitudes about regulation and growth, consistent with a referencebias hypothesis (Brody and Zahran 2007). Rates of population change influence not only people's perception of sprawl or development problems, but also their endorsement of environmental rules. Conversely, people were less likely to support environmental rules when they lived in counties with high unemployment. Controlling for other factors, the rate of primary-sector employment did not affect views about conservation or environmental rules, but did predict perceptions of sprawl or development problems. Such problems, realistically, appear less acute in places that have retained more primary industry.

Place effects also entered the analysis in the form of random intercepts, representing county-tocounty differences in mean probabilities (more precisely, in mean log odds) unexplained by the measured predictors. These 19 rural counties vary in countless respects besides rates of growth, unemployment and primary-sector employment. A shared context could influence residents within each county in similar ways, raising the statistical problem of correlated errors. For example, one of our Northeast counties had seen several pulp and paper mills close down within the past few years. Perhaps that explains why people there were more willing than those in a neighboring county to choose jobs over conservation, despite a lower long-term unemployment rate. The Pacific Northwest, where relatively many respondents (although still a minority) thought environmental rules had been bad, is a region with highprofile controversies over the protection of spotted owls and salmon. In our Rocky Mountain counties, the growing economy based on recreation and natural amenities gives people less reason to perceive conflict between jobs and conservation. In Appalachia, on the other hand, coal mining interests have cast debates over mountaintop-removal mining as a choice between jobs and conservation. No model could explicitly consider all such contingencies, but random intercepts provide a way to represent their net effect for each place.

Growth and job indicators thus had the expected effects not only after adjusting for individual social-position and ideological characteristics, but also after allowing for unexplained mean differences across counties. Individual perspectives, as social phenomena, are emplaced (Gieryn 2000) in geographic locations and related physical, practical and symbolic structures. These findings illustrate some ways in which environmental views are embedded in such place-specific contexts. The application of mixed-effects modeling to study place effects in integrated individual/contextual datasets opens new possibilities for environmental sociology, following up on Dunlap and Catton's (1979) call to study the ways that environments can influence (as well as be influenced by) human societies and behavior. 


\section{Notes}

[1] Our use of counties rather than smaller communities as the units for "place" represents a practical tradeoff, necessary both for obtaining a selection of natural and social environmental measures, and for obtaining survey subsamples large enough to distinguish pattern from noise. There are substantial variations between the 19 counties chosen, but they are not internally very large (as are some other Western counties) or diverse (as counties combining metropolitan and rural areas would be). Empirically, a county-based approach works reasonably well, as seen in Figures 2, 4, 6 and Table 2. Other authors (Zahran et al. 2006; Brody et al. 2008) also report evidence for county-level effects on environmental views. Future research could experiment with different designs to explore scaling issues further.

[2] Although the CERA surveys include 7,842 respondents, only 5,834 observations without missing values on any of the 14 variables contribute to the Table 2 analyses. About 1,000 of these lost observations are regained if we set aside income, which as usual on surveys produced many missing values. Running the same models without income (so $n>6,800$ ) yields substantially similar results, however, including all of the place and interaction effects. Because including income seems not to bias the conclusions either way, we kept it in the Table 2 models for comparability with previous studies.

Albright (2007) provides a simple comparison of mixed-modeling procedures (found in Stata, SAS and SPSS) with the hierarchical linear modeling (HLM) software developed by Raudenbush and Bryk (2002; also Raudenbush et al. 2005), which is popular in some areas such as education. More detailed explanation of mixed modeling and its correspondences with HLM can be found in RabeHesketh and Skrondal (2008). Briefly, HLM approaches multilevel modeling through a two-step formulation, specifying separate equations (for example) for level 1 and level 2 effects. In practice these equations cannot be estimated separately, so the software internally substitutes to form a single reduced equation for estimation. Mixed-effects modeling works directly with the reduced equation, giving it a "less multilevel" appearance than HLM even when both describe mathematically equivalent models. Conversely, HLM users may not realize that effects apparently at different levels can equivalently be represented as fixed or random effects within a single reduced equation. Rabe-Hesketh and Skrondal (2008:171) also note some cultural differences between HLM and mixed-modeling applications: "Papers using [HLM] tend to include more cross-level interactions and more random coefficients in the models (because the level-2 models look odd without residuals) than papers using for instance Stata." Our choices regarding which random effects and interaction terms to include in the Table 2 model were guided by substantive needs and statistical testing.

[3] Education and party were centered as mean deviations to simplify interpretation of main effects, and reduce multicollinearity with their product. We fit these models using Stata's xtmelogit procedure (StataCorp 2007; Rabe-Hesketh and Skrondal 2008; Hamilton 2009). Table 1 notes the dummy-variable recoding employed for binomial logit modeling. In terms of the general conclusions, it does not matter whether missing values on the original 3-value dependent variables are coded as missing on the dummyvariable version, or as zeroes. We also replicated the analyses using the dependent variables in their original 3-value ordinal forms, using both a mixed-effects versions of ordered logit regression (an ordinal technique, implemented in GLLAMM) and linear mixed models. All three methods produced generally similar results, as did fixed-effects models with survey weighting. Our main conclusions, including place and interaction effects, thus appear analytically robust. The binary logit models presented in Table 2 offer advantages of being simpler to fit or explain than ordered-logit models, and statistically more appropriate than linear models. 
[4] We also considered county-level air pollution measures as possible predictors, but found no evidence that they influenced environmental views among these rural respondents. Exploratory analyses (not shown) included work with EPA emissions data on seven criteria pollutants, from either point or nonpoint sources. Emissions measures, in log form, appeared largely unrelated to opinions. This null finding held true whether pollutants were considered individually or combined into indexes by principal components. Air pollution monitoring data (including the Air Quality Index), although potentially of interest to other studies, are not recorded for most of these rural counties.

[5] Because education and party were centered at their means, the main effects for education in Table 2 can be interpreted as the effects of education for respondents of "average" political party identification (about 3.7 on a scale from $1=$ strong Democrat to $7=$ strong Republican). Similarly, main effects for party describe the effects of party for respondents with "average" education. 


\section{References}

AAPOR. 2006. Standard Definitions: Final Disposition of Case Codes and Outcome Rates for Surveys, 4th edition. Lenexa, KS: American Association for Public Opinion Research.

Albright, J.J. 2007. "Estimating Multilevel Models Using SPSS, Stata, and SAS." Indiana University. Retrieved April 22, 2008 (http://www.indiana.edu/ statmath/stat/all/hlm/hlm.pdf).

Brody, S.D. and S. Zahran. 2007. "Linking Particulate Matter and Sulphur Concentrations to Air Pollution Annoyance: Problems of Measurement, Scale and Control" (commentary on Jacquemin et al. 2007). International Journal of Epidemiology, doi: 10.1093/ije/dym143

Brody, S.D., S. Zahran, A. Vedlitz and H. Grover. 2008. "Examining the Relationship Between Physical Vulnerability and Public Perceptions of Global Climate Change in the United States. Environment and Behavior 40(1):72-95.

Convert, B. and J. Heilbron. 2007. "Where Did the New Economic Sociology Come From?" Theory and Society 36:31-54.

Davidson, D.J. and W.R. Freudenburg. 1996. "Gender and Environmental Risk Concerns: A Review and Analysis of Available Research." Environment and Behavior 28:302-339.

Dietz, T., A. Fitzgerald and R. Shwom. 2005. "Environmental Values." Annual Review of Environment and Resources 30:335-374.

Dietz, T., A. Dan and R. Shwom. 2007. "Support for Climate Change Policy: Social Psychological and Social Structural Influences.” Rural Sociology 72:185-214.

Drori, I. and E. Yuchtman-Yaar. 2002. "Environmental Vulnerability in Public Perceptions and Attitudes: The Case of Israel's Urban Centers.” Social Science Quarterly 83(1):53-63.

Dunlap, R.E. and W.R. Catton, Jr. 1979. "Environmental Sociology.” Pp. 243-273 in Inkeles, Coleman, and Turner (eds.) Annual Review of Sociology. Palo Alto, CA: Annual Reviews.

Dunlap, R.E. and K.D. Van Liere. 1978. “The 'New Environmental Paradigm'.” The Journal of Environmental Education 9:10-19.

Dunlap, R.E., C. Xiao and A.M. McCright. 2001. "Politics and Environment in America: Partisan and Ideological Cleavages in Public Support for Environmentalism." Environmental Politics 10(4):23-48.

Dunlap, R.E. and A.M. McCright. 2008. "A Widening Gap: Republican and Democratic Views on Climate Change." Environment September/October

http://www.environmentmagazine.org/Archives/Back\%20Issues/September-October\%202008/dunlap-full .html 
Elliott, S.J., D.C. Cole, P. Krueger, N. Voorberg and S. Wakefield. 1999. "The Power of Perception: Health Risk Attributed to Air Pollution in an Urban Industrial Neighbourhood." Risk Analysis 19(4):621-634.

Finucane, M.L., P. Slovic, C,K. Mertz, J. Flynn and T.A. Satterfield. 2000. "Gender, Race, and Perceived Risk: the 'White Male' Effect.” Health, Risk and Society 2(2):159-172.

Freudenburg, W.R. 2000. "Social Constructions and Social Constrictions: Toward Analyzing the Social Construction of 'The Naturalized' as Well as 'The Natural."' Pp. 103-119 in G. Spaargaren, A.P.J. Mol and F.H. Buttel (eds.), Environment and Global Modernity. London: Sage.

Gieryn, T.F. 2000. “A Space for Place in Sociology.” Annual Review of Sociology 26:463-496.

Grabher, G. 2006. "Trading Routes, Bypasses, and Risky Intersections: Mapping the Travels of 'Networks' Between Economic Sociology and Economic Geography." Progress in Human Geography 30:163-189.

Granovetter, M. 1985. "Economic Action and Social Structure: The Problem of Embeddedness." American Journal of Sociology 91:481-510.

Guagnano, G.A. and N. Markee. 1995. "Regional Differences in the Sociodemographic Determinants of Environmental Concern" Population and Environment 17(2):135-149.

Hamilton, L.C. 1985. "Concern about Toxic Wastes: Three Demographic Predictors." Sociological Perspectives 26(4):355-374.

Hamilton, L.C. 2007a. "Views from the Heartland." Snapshots of Social Change (December). Durham, NH: Carsey Institute. (http://www.carseyinstitute.unh.edu/snapshot_kansas.html)

Hamilton, L.C. 2007b. "Community and Environment in Rural America - Survey Update." Snapshots of Social Change (December). Durham, NH: Carsey Institute.

(http://www.carseyinstitute.unh.edu/snapshot_.CERA.html)

Hamilton, L.C. 2008. "Who Cares about Polar Regions? Results from a Survey of U.S. Public Opinion." Arctic, Antarctic, and Alpine Research 40(4):671-678.

Hamilton, L.C. 2009. Statistics with Stata, version 10. Belmont, CA: Cengage.

Hamilton, L.C. forthcoming. "Education, Politics and Opinions about Climate Change: Evidence for Interaction Effects." Climatic Change

Hamilton, L.C., L.R. Hamilton, C.M. Duncan and C.R. Colocousis. 2008. Place Matters: Challenges and Opportunities in Four Rural Americas. Reports on Rural America 1(4). Durham, NH: Carsey Institute.

Hamilton, L.C. and B.D. Keim. 2009. "Regional Variation in Perceptions about Climate Change." International Journal of Climatology doi: 10.1002/joc.1930 
Hamilton, L.C., L.R. Hamilton, C.M. Duncan and C.R. Colocousis. 2008. Place Matters: Challenges and Opportunities in Four Rural Americas. Reports on Rural America 1(4). Durham, NH: Carsey Institute.

Jacquemin, B., J. Sunyer, B. Forsberg, T. Götshi, L. Bayer-Oglesby, U. Ackermann-Liebrich, R. de Marco, J. Heinrich, D. Jarvis, K. Torén and N. Künzli. 2007. "Annoyance Due to Air Pollution in Europe.” International Journal of Epidemiology doi: 10.1093/ije/dym042

Jacques, P.J., R.E. Dunlap and M. Freeman. 2008. “The Organisation of Denial: Conservative Think Tanks and Environmental Scepticism.” Environmental Politics 17(3):349-385.

Johnson, K. 2006. Demographic Trends in Rural and Small-Town America. Reports on Rural American 1(1). Durham, NH: Carsey Institute.

Jones, R.E. and R.E. Dunlap. 1992. "The Social Bases of Environmental Concern: Have They Changed over Time?" Rural Sociology 57:28-47.

Kahan, D.M., D. Braman, J. Gastil, P. Slovic and C.K. Mertz. 2005. "Gender, Race and Risk Perception: the Influence of Cultural Status Anxiety.” New Haven, CT: Public Law \& Legal Theor Research Paper No. 86.

Klineberg, S.L., M. McKeever and B. Rothenbach. 1998. "Demographic Predictors of Environmental Concern: it Does Make a Difference How It’s Measured.” Social Science Quarterly 79:734-753.

Krosnick, J.A., A.L. Holbrook, L. Lowe and P.S. Visser. 2006. "The Origins and Consequences of Democratic Citizens' Policy Agendas: A Study of Popular Concern about Global Warming." Climatic Change 77(1-2):7-43.

Lauer, S.R. 2005. "Entrepreneurial Processes in an Emergent Resource Industry: Community Embeddedness in Maine's Sea Urchin Industry.” Rural Sociology 70:145-166.

Lee, E.S. and R.N. Forthofer. 2006. Analyzing Complex Survey Data, 2nd edition. Thousand Oaks: Sage.

Leiserowitz, A. 2006. "Climate Change Risk Perception and Policy Preferences: The Role of Affect, Imagery, and Values.” Climatic Change 77(1-2):45-72.

Lorenzoni I. and N.F. Pidgeon. 2006. "Public Views on Climate Change: European and USA Perspectives." Climatic Change 77(1-2):73-95.

Luke, D.A. 2004. Multilevel Modeling. Thousand Oaks, CA: Sage.

McCright, A.M. and R.E. Dunlap. 2000. "Challenging Global Warming as a Problem: An Analysis of the Conservative Movement's Counter-claims.” Social Problems 50(3):348-373. 
McCright, A.M. and R.E. Dunlap. 2003. "Defeating Kyoto: The Conservative Movement's Impact on the U.s. Climate Change Policy.” Retrieved June 25, 2008 (http://stephenschneider.stanford.edu/Publications/PDF_Paper

Olofsson, A. and S. Öhman. 2006. "General Beliefs and Environmental Concern: Transatlantic Comparisons." Environment and Behavior 38:768-790.

Pew. 2004. "Polls Face Growing Resistance, but Still Representative.” Pew Research Center, April 20. Retrieved on January 11, 2009 (http://people-press.org/report/211/).

Pew. 2007. "Global Warming: A Divide on Causes and Solutions." Pew Research Center, January 24. Retrieved on December 14, 2009 (http://people-press.org/reports/pdf/303.pdf).

Rabe-Hesketh, S. and A. Skrondal. 2008. Multilevel and Longitudinal Modeling Using Stata, 2nd edition. College Station, TX: Stata Press.

Raudenbush, S.W. and A.S. Bryk. 2002. Hierarchical Linear Models: Applications and Data Analysis Methods, 2nd edition. Newbury Park, CA: Sage.

Raudenbush, S.W., A.S. Bryk, Y.F. Cheong \& R. Congdon. 2005. HLM 5: Hierarchical Linear and Nonlinear Modeling. Lincolnwood, IL: Scientific Software International.

Shwom, R., A. Dan and T. Dietz. 2008. "The Effects of Information and State of Residence on Climate Change Policy Preferences." Climatic Change 90:343-358.

Slimak, M.W. and T. Dietz. 2006. "Personal Values, Beliefs, and Ecological Risk Perception.” Risk Analysis 26(5):1689-1705.

StataCorp. 2007. Stata Longitudinal/Panel Data Analysis Manual, Release 10. College Station, TX: Stata Press.

UCS. 2007. Smoke, Mirrors and Hot Air: How ExxonMobil Uses Big Tobacco's Tactics to Manufacture Uncertainty about Climate Science. Cambridge, MA: Union of Concerned Scientists: Cambridge.

Van Liere, K.D. and R.E. Dunlap. 1980. "The Social Bases of Environmental Concern: A Review of Hypotheses, Explanations and Empirical Evidence.” Public Opinion Quarterly 44(2):181-197.

Viscusi, W.K. and R.J. Zeckhauser. 2005. "The Perception and Valuation of the Risks of Climate Change: A Rational and Behavioral Blend.” Social Science Research Network, http://ssrn.com/abstract=832645.

Whitfield, S.C., E.A. Rosa, A. Dan and T. Dietz. 2009. "The Future of Nuclear Power: Value Orientations and Risk Perception." Risk Analysis 29(3):425-437.

Wood, B.D. and A. Vedlitz. 2007. "Issue Definition, Information Processing, and the Politics of Global Warming." American Journal of Political Science 51(3):552-568. 
Xiao, C. and A.M. McCright. 2007. "Environmental Concern and Sociodemographic Variables: A Study of Statistical Models." Journal of Environmental Education 38:3-13.

Zahran, S., S.D. Brody, H. Grover and A. Vedlitz. 2006. "Climate Change Vulnerability and Policy Support." Society and Natural Resources 19:771-789. 
Table 1: Dependent variables sprawl, conserve and rules assess views on local environmental issues. The percentages shown below and in Figures 1-6 (based on 7,323 to 7,626 responses) reflect minor adjustments for sampling design and bias. In telephone interviews, choices were read in the same order as the initial question. Dummy variable codes for the logit analysis of Table 2 are given in parentheses.

sprawl

"I'm going to read a list of environmental issues that might be problems in some rural places. With regard to the place where YOU live, for each issue I'd like to know whether you think this has had no effect, had minor effects, or had major effects ON YOUR FAMILY OR COMMUNITY OVER THE PAST 5 YEARS?

Urban sprawl or rapid development of the countryside."

$$
\begin{array}{ll}
49 \% & \text { No effect }(0) \\
28 \% & \text { Minor effects }(0) \\
23 \% & \text { Major effects }(1)
\end{array}
$$

conserve

"For the future of your community, do you think it is more important to use natural resources to create jobs, or to conserve natural resources for future generations?"

$29 \%$ Use natural resources to create jobs (0)

$28 \%$ Creating jobs and conserving resources are both equally important (0)

$43 \% \quad$ Conserve natural resources for the future (1)

rules

"Have conservation or environmental rules that restrict development generally been a good thing for your community, a bad thing, or have they had no effect?"

$13 \%$ Conservation rules have been a bad thing here $(0)$

$45 \%$ Conservation rules have had no effect here $(0)$

$41 \%$ Conservation rules have been a good thing here (1) 
Table 2: Mixed-effects logit regression of environmental views on characteristics of individual respondents (including education $\times$ party interaction) and the counties in which they live $(n=5,834)$. Logit regression coefficients and $z$ test probabilities for fixed-effects coefficients and intercepts are shown, together with standard deviations and their standard errors for random intercepts. Terms significant at $\alpha=.01$ emphasized in bold.

\begin{tabular}{|c|c|c|c|c|c|c|}
\hline \multirow[b]{3}{*}{ Predictors } & \multicolumn{5}{|c|}{ Environmental views } & \\
\hline & \multicolumn{2}{|c|}{ Sprawl impacts } & \multicolumn{2}{|c|}{ Conservation over jobs } & \multicolumn{2}{|c|}{ Environmental rules good } \\
\hline & coef. & $p$ & coef. & $p$ & coef. & $p$ \\
\hline \multicolumn{7}{|l|}{$\begin{array}{l}\text { Individual-level } \\
\text { fixed effects }\end{array}$} \\
\hline sex (female) & -.130 & .065 & .209 & .000 & .025 & .669 \\
\hline race (nonwhite) & .169 & .146 & -.275 & .004 & -.301 & .002 \\
\hline age & -.001 & .778 & -.006 & .001 & .001 & .557 \\
\hline income & -.117 & .000 & -.003 & .882 & .030 & .169 \\
\hline education & -.067 & .003 & .064 & .001 & .089 & .000 \\
\hline party (Republican) & -.036 & .032 & -.061 & .000 & -.041 & .003 \\
\hline education xparty & -.028 & .003 & -.031 & .000 & -.029 & .000 \\
\hline religious & -.050 & .055 & -.078 & .000 & -.029 & .180 \\
\hline newcomer & -.291 & .003 & .204 & .009 & .172 & .030 \\
\hline \multicolumn{7}{|l|}{$\begin{array}{l}\text { County-level } \\
\text { fixed effects }\end{array}$} \\
\hline unemployment & -.039 & .356 & -.084 & .001 & -.059 & .010 \\
\hline population growth & .070 & .000 & .013 & .149 & .050 & .000 \\
\hline primary sector & -.066 & .000 & -.019 & .072 & -.001 & .933 \\
\hline Fixed intercept & -.120 & .745 & .764 & .001 & -.250 & .264 \\
\hline $\begin{array}{l}\text { County-level } \\
\text { random intercept }\end{array}$ & estimate & std. error & estimate & std. error & estimate & std. error \\
\hline standard deviation & .307 & .066 & .165 & .041 & .132 & .043 \\
\hline LR test vs. fixed-effects: & .000 & & .000 & & .005 & \\
\hline "correct" classifications & $78 \%$ & & $62 \%$ & & $65 \%$ & \\
\hline
\end{tabular}



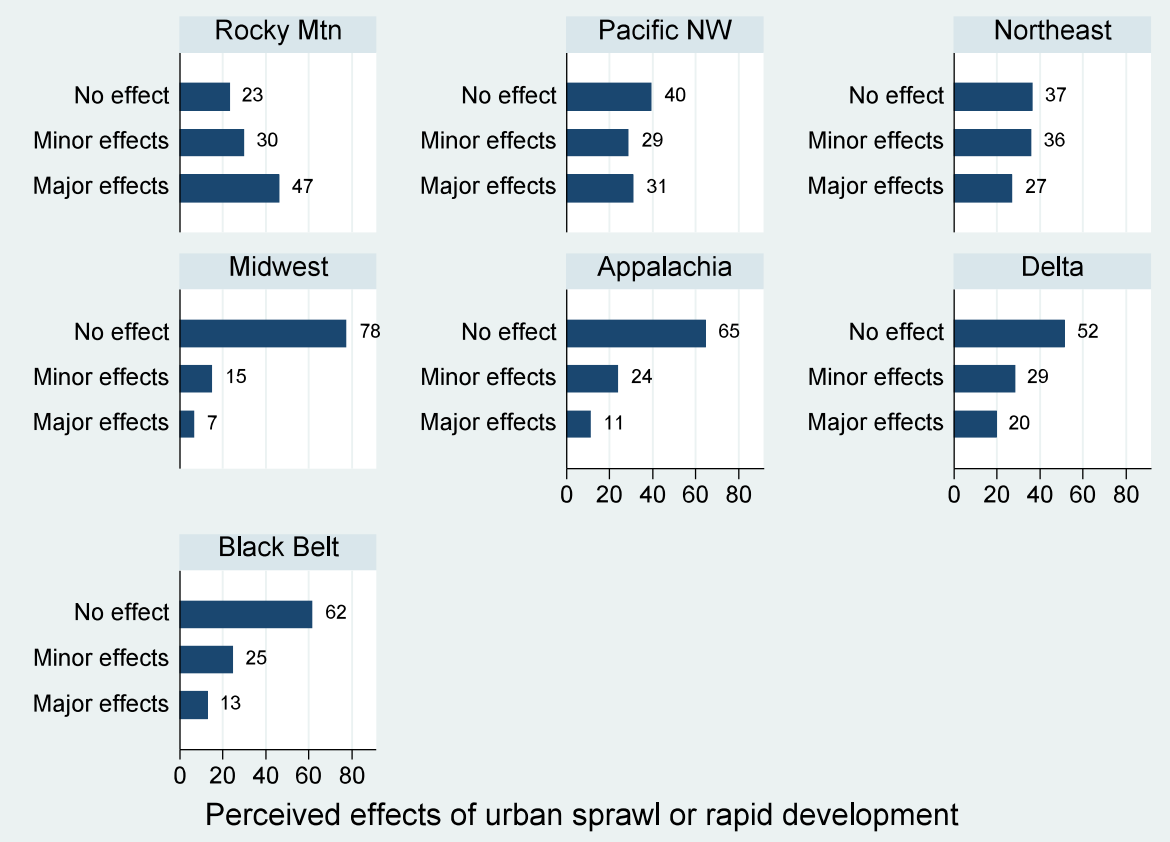

Figure 1: Has urban sprawl or rapid development of the countryside affected your family or community over the past 5 years?

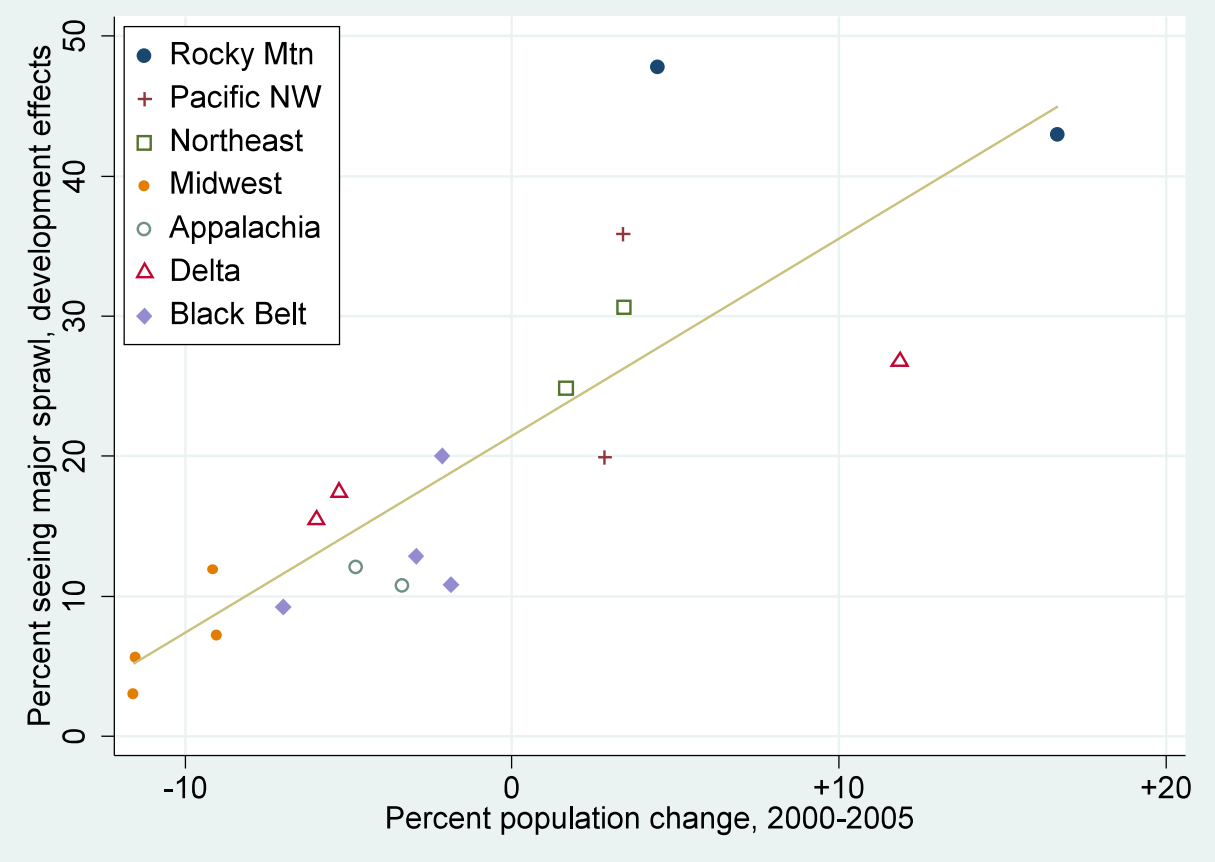

Figure 2: Percent perceiving major effects from urban sprawl or rapid development, vs. recent population growth rates in 19 counties (Pearson $r=.84$, Spearman $r=.89$ ). 

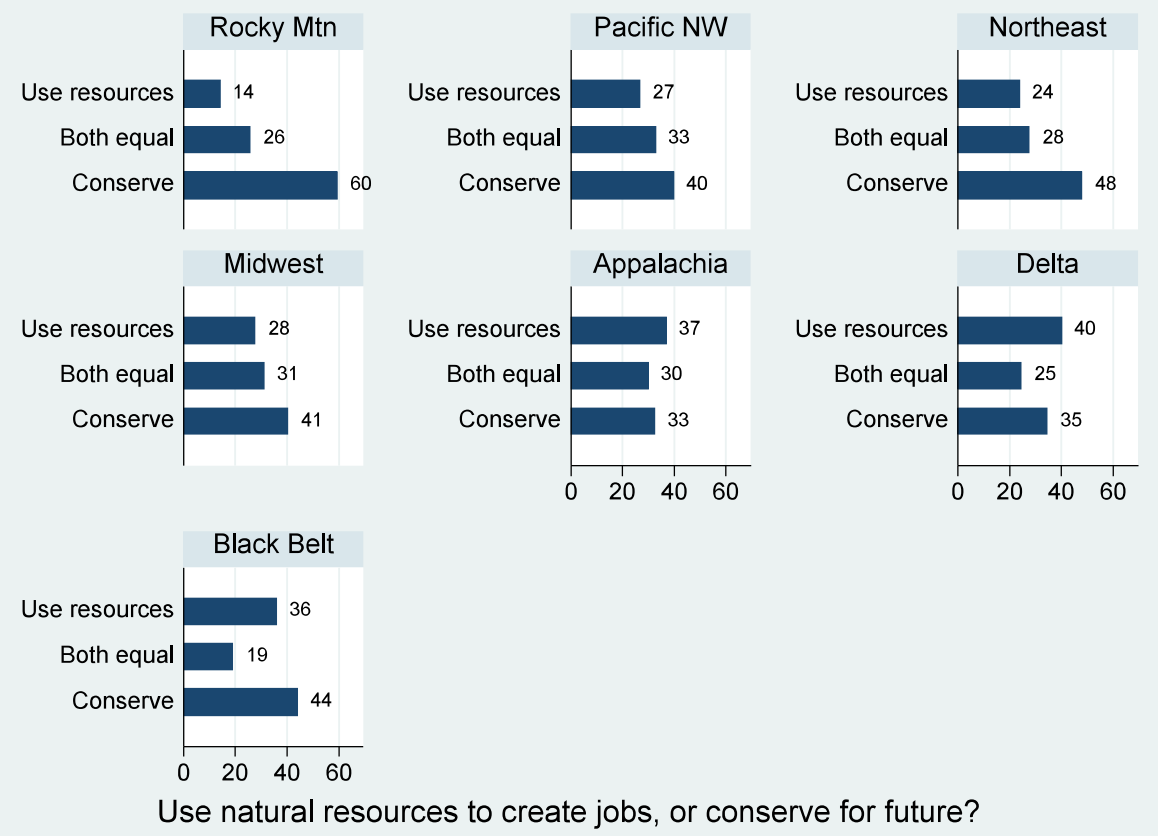

Figure 3: Do you think it is more important to use natural resources to create jobs, or to conserve resources for future generations?

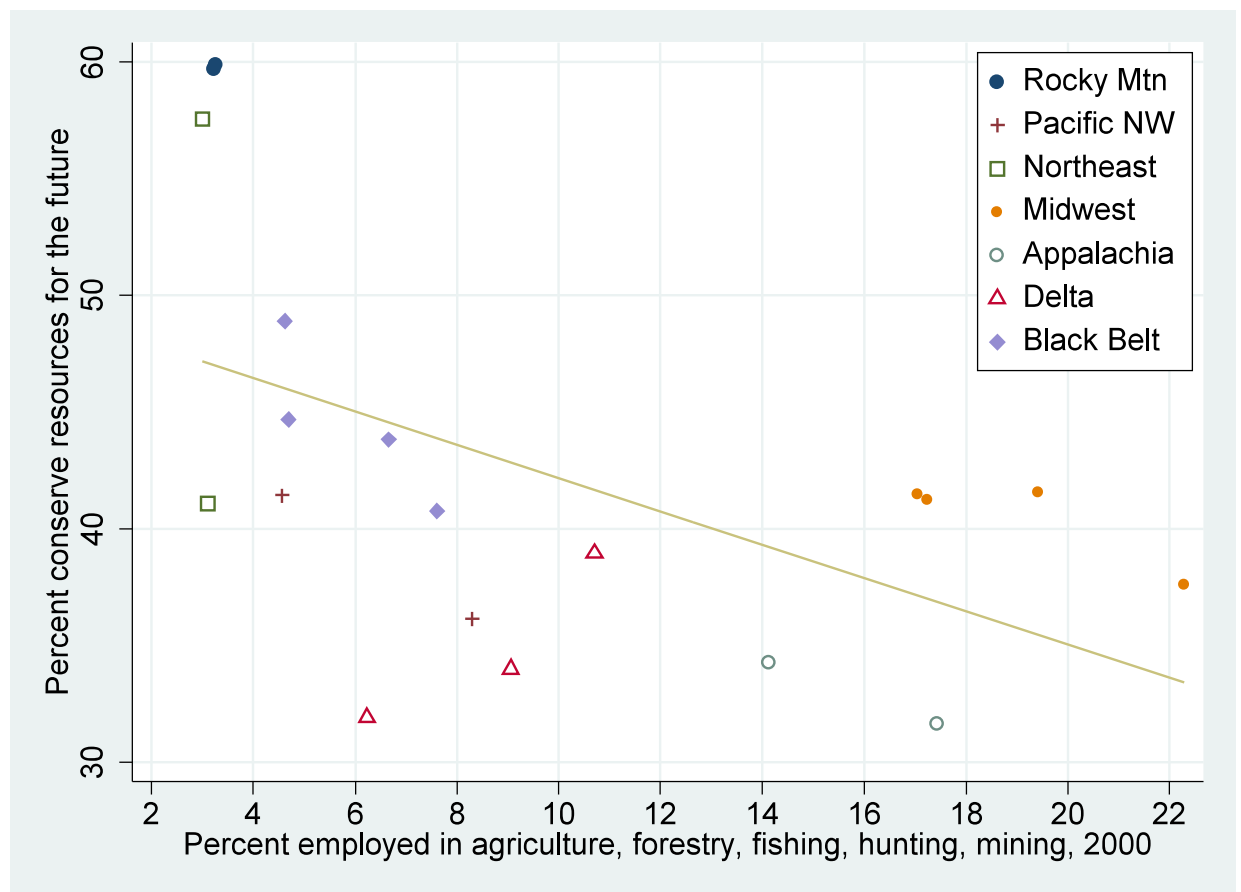

Figure 4: Percent favoring conservation of resources for future generations, vs. percent employed in primary industry in 19 counties (Pearson $r=-.53$, Spearman $r=-.55$ ). 

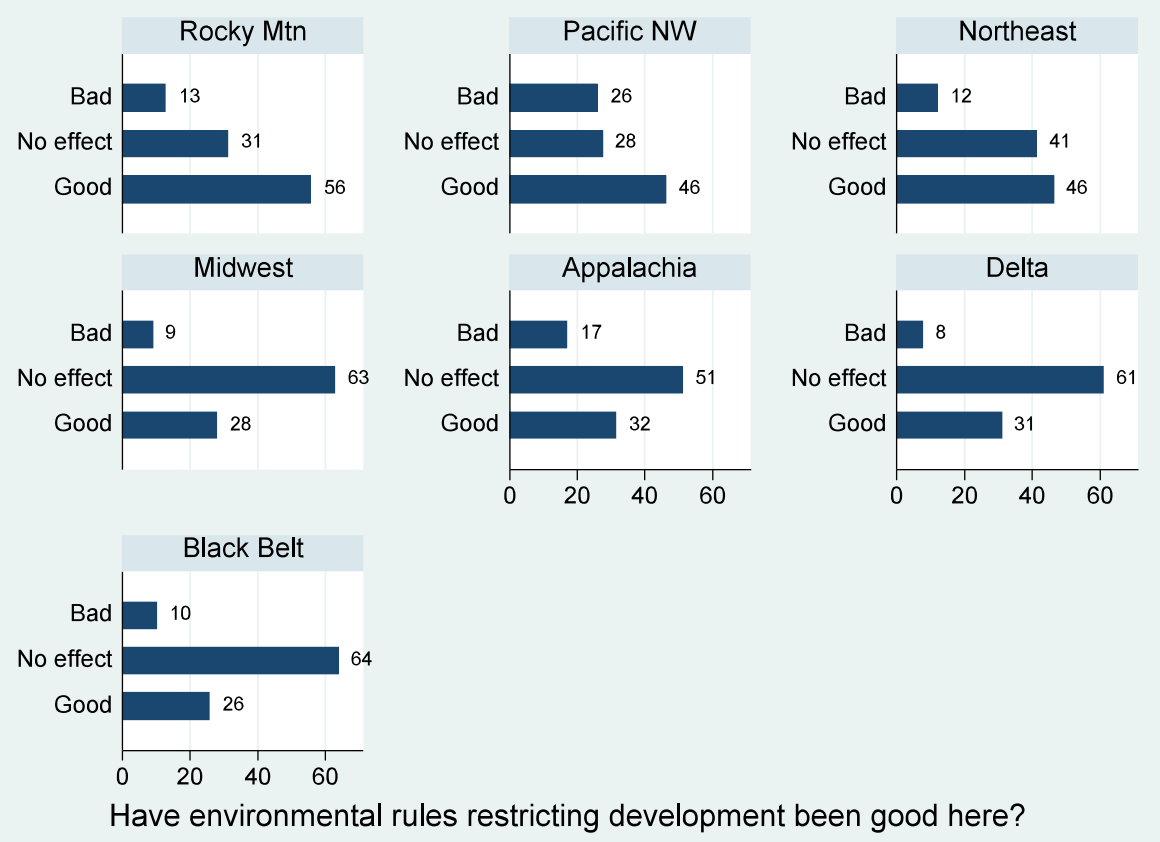

Figure 5: Have conservation or environmental rules that restrict development generally been a good thing for your community?

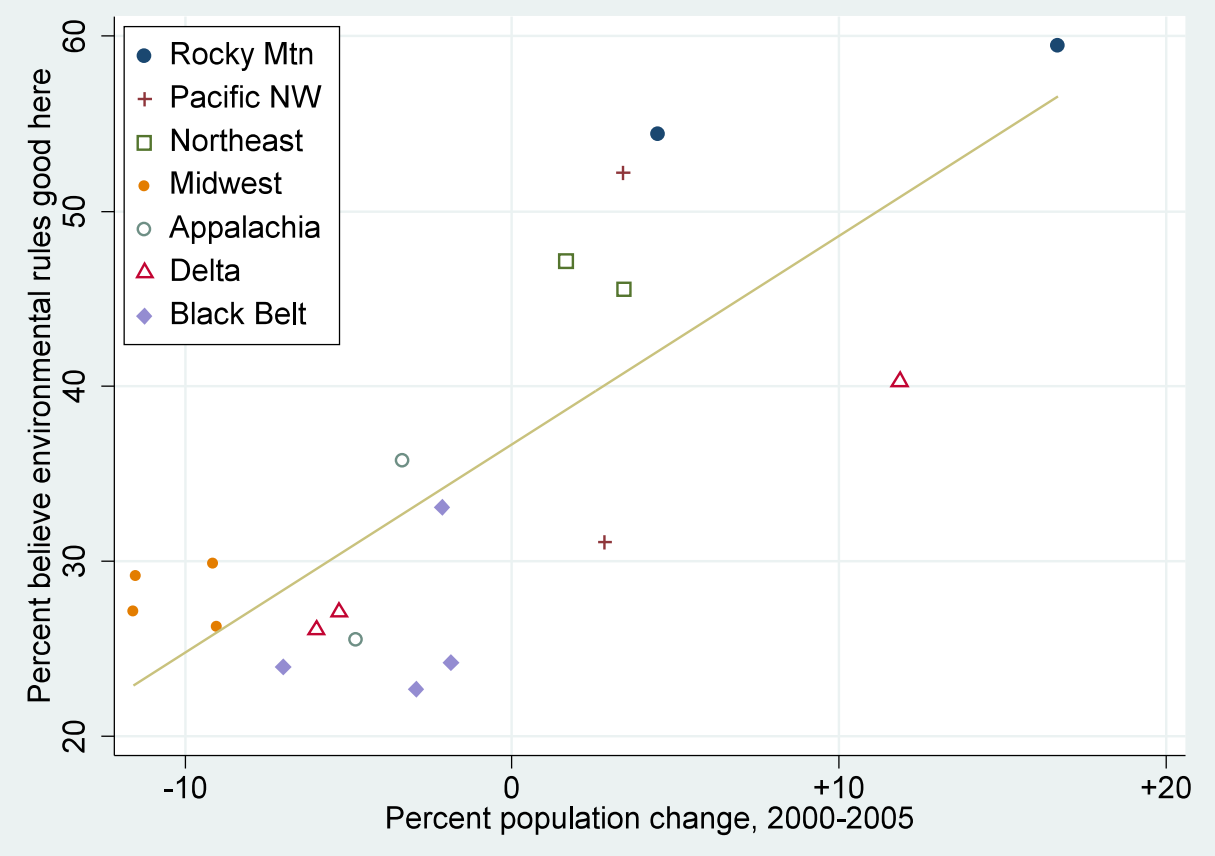

Figure 6: Percent believing that environmental rules restricting development have been good here, vs. recent population growth in 19 counties (Pearson $r=.78$, Spearman $r=.65$ ). 